\title{
A Case Report - An Isolated Congenital Type C Quadrileaflet Aortic Valve: A Rare Cause of Aortic Insufficiency
}

\author{
Dr. J. Rajendra Kumar 1 *, Dr. Mamta B. Kumbhare 2*, \\ Dr. P. Goutham Kumar 1**, Dr.T.Vishal Goud $1 * * *$ \\ (1*Associate Professor, 1 **and $1 * * *$ Third Year PG student, Department of Medicine CAIMS, Bommakal, \\ Karimnagar (A.P.) India - 505 001) \\ (2 *Senior Specialist Anesthesia, Dhanvanthari Hospital, NTPC, RSTPS, Jyothi Nagar. District Karimnagar \\ (AP) India - 505 215)
}

\begin{abstract}
An accessory coronary cusp in aortic valve is a rare congenital cardiovascular malformation with an estimated incidence of 0.003 to $0.043 \%$ of all congenital heart disease. It is also describe as a quadricuspid aortic valve $(Q A V)$. Several different anatomical variations of quadricuspid aortic valve have been described. Current technology enables noninvasive diagnosis in most cases. Here we reported a rare an isolated congenital type ' $C$ ' $Q A V$ with aortic regurgitation; hence it was worth reporting this interesting case.
\end{abstract}

Key word: Qadricuspid aortic valve, Quadrileaflet aortic valve, Aortic valve, Anomalies, An accessory coronary cusp.

\section{Introduction:}

Since the first case of QAV was published in 1969, the total numbers of reported cases has reached approximately 200 [6]. It has in the past been an incidental finding at open heart surgery or at autopsy. There have in recent years been a few case reports with increasing use of echocardiography. Now a days an Echocardiography [3], Computed tomographic angiography, Magnetic resonance imaging or Aortography are the leading mode of detection, followed by surgery, autopsy and aortography .

QAV were associated with other congenital cardiac malformation in $18.3 \%$ of cases. Anomalies of the coronary arteries were the most frequent cardiac defects associated with QAV [7].

\section{Case Report:}

A 32 year old male presented with almost one year history of NYHA II dysponea. . On physical examination his blood pressure was 140/80 $\mathrm{mmHg}$, pulse $80 /$ minute, regular and a diastolic grade $3 / 6$ murmur was heard at Erb's area. Murmur was increased by hand grip exercise and squatting position and decreased by standing from squatting and valsalva maneuver. ECG(figure 4) and CXR were normal. Hematological finding with blood biochemistry and renal function test were with in normal limits. Trans - thoracic 2 dimensional echocardiography (TTE) was done in all views which revealed a quasricuspid aortic valve. Planimetric evaluation of four separate cusps was performed on an end diastolic still frame in parasternal short axis view at aortic valve level, which shows two equal large size and two equal small size cusps of QAV and cross shaped QAV ( Figure1).Color flow Doppler echocardiography (figure 3) at aortic valve reveled moderate aortic regurgitation. Left ventricular (LV) end diastolic dimension and LV end systolic dimension and LV function were normal. There were no associate cardiac anomalies detected by TTE. We advised cardiac catherization but he refused.

\section{Discussion:}

QAV was first identified on autopsy by Balington in 1862, the first in vivo description dating from 1968, by Robicsek et-al [7]. Systemic autopsy studies have estimated its incidence between 0.003 and $0.008 \%$, while a more recent echocardiographic review reported an incidence of $0.043 \%$.[5].

Most cases of QAV have been discovered incidentally at autopsy or during aortic valve surgery but now a days with advance non invasive technology like 2 Dimensional echocardiography, 3 Dimensional echocardiography Computed tomographic angiography, Magnetic resonance imaging QAV can be diagnose easily. Various embryological mechanisms have been suggested for origin of QAV, including erosion of one of the valve cushions and septation of a normal valve cushion as a result of inflammatory episode. In 1973, Hurwitz and Roberts classified the quadricuspid semilunar valve according to their anatomical variation [1]. They described seven variation forms from A to $\mathrm{G}$ (Table No 1). The most frequent anatomical variation is Type " $\mathrm{A}$ " and Type "B" and both are more likely to develop aortic regurgitation than other anatomical variant. According to the 
Hurwitz and Roberts classification system our patient had two equal larger and two equal smaller cusps (Type "C"), leading to moderate aortic regurgitation due to unequal size of cusps[2,3]. Pure aortic regurgitation was found in almost $75 \%$ of cases, while $16 \%$ of the quasricuspid valve functions normally [2, 3]. Very rarely QAV is associated with aortic stenosis.

Congenital QAV is usually an isolated lesion but several congenital cardiac abnormalities have been described. The most prevalent cardiac malformations associated with QAV are coronary artery anomalies, which have been reported in $10 \%$ of cases, because of the additional cusp, the origin of the left and right coronary artery may not be at their usual sites [7]. Ventricular septal defect [8], Patient ductus arteiosus, pulmonary stenosis, Sub aortic stenosis, Hypertrophic cardiomyopathy and complete congenital heart block and also cases of bacterial endocarditis affecting a QAV have been reported.

In our case patient had NYHA II symptoms and TTE reveled QAV with moderate AR and Normal LV dimension and function. Patient was advised cardiac catherization but he refused and was treated medically (Diuretic and ACE inhibitors) and we advised for regular follow up. On the basis of clinical examination and TTE finding he was diagnosed as an isolated congenital type "C" QAV with moderate aortic regurgitation.

\section{Conclusion:}

The QAV is a rare congenital heart defect with a high potential for serious complications. The anatomic variation with four equal cusps appear to be the most common type of QAV, further the great majority of QAV do not have a normal function and often require surgery. Patient with a QAV are not simply academic interest, rather they require careful clinical evaluation and close follow up.

\section{References:}

1. Hurwitz LE, Roberts WC: Quadricuspid semilunar valve. Am J Cardiol 1973, 31:623-626?

2. Recupero A, Pugliatti P, Rizzo F, Arrigo F, Coglitore S : Quadricuspid aortic valve: a rare cause of aortic insufficiency diagnosed by Doppler echocardiography. Report of two cases and review of the literature. Ital Heart J 2005, 6:927-30.

3. Weidong R, Xin C, Jun Y. Quadricuspid aortic valve diagnosed by transthoracic and multiplane transesophagel echocardiography. ChinUltrason med magazine 2000; 16:1.

4. Sakai Y, Tomita H, Ukae S. An aortic valve with four leaflets. Cardiol Young 2000; 10:538.

5. Feldman BJ, Khandheria BK, Warnes CA,et-al. Incidence,description and functional assessment of isolated quadricuspid aortic valves. Am J cardiol, 1990; 65:937- 938.

6. Tutarel O. The quadricuspid aortic valve. A comprehensive review. J Heart Valve Dis 2004; 13:534-37.

7. Balington J, quoted by Robicsek F, Sanger PW, et-al. Congenital quadricuspid aotic valve with displacement of left coronary orifice. Collected works on Cardiopulmonary Diseases.1968; 14:87-90.

8. Stanescu CM, Branidou K. A case of 75 year old survivor of unrepaired tetralogy of Fallot and quadricuspid aortic valve. Eur J Echo 2008; 9:167-70.

Table 1. Hurwitz and Roberts anatomical classification of QAV.

\begin{tabular}{|l|l|}
\hline Type & Description \\
\hline A & Four equal cusps. \\
\hline B & Three equal cusps and one smaller cusp. \\
\hline C & Two equal larger cusps and two equal smaller cusps. \\
\hline D & One large, two intermediate and one small cusp. \\
\hline E & Three equal cusps and one larger cusp. \\
\hline F & Two equal larger cusps and two unequal smaller cusps. \\
\hline G & Four unequal cusps. \\
\hline
\end{tabular}




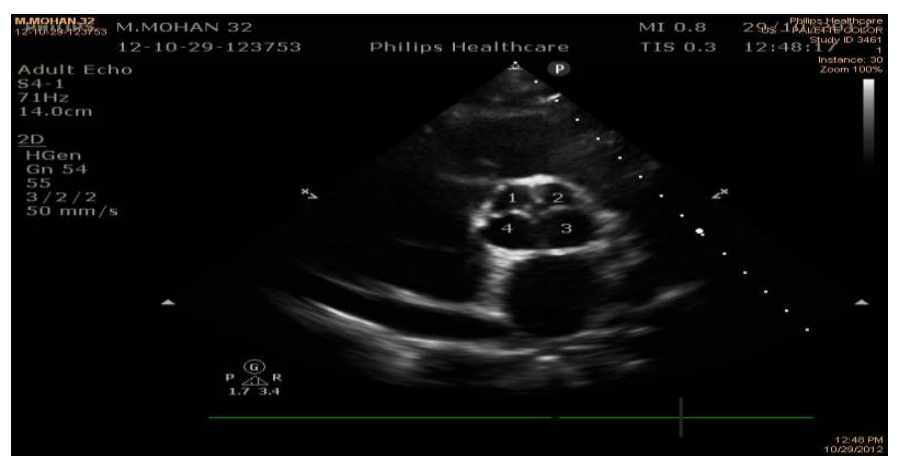

Figure 1. Transthoracic 2 dimensional echocardiogram image in parasternal short axis(PSAX) view at aortic valve in diastole showing two equal lager (number 3 and 4 ) and two equal small

(Number 1 and 2) cusps of Type "C" QAV.

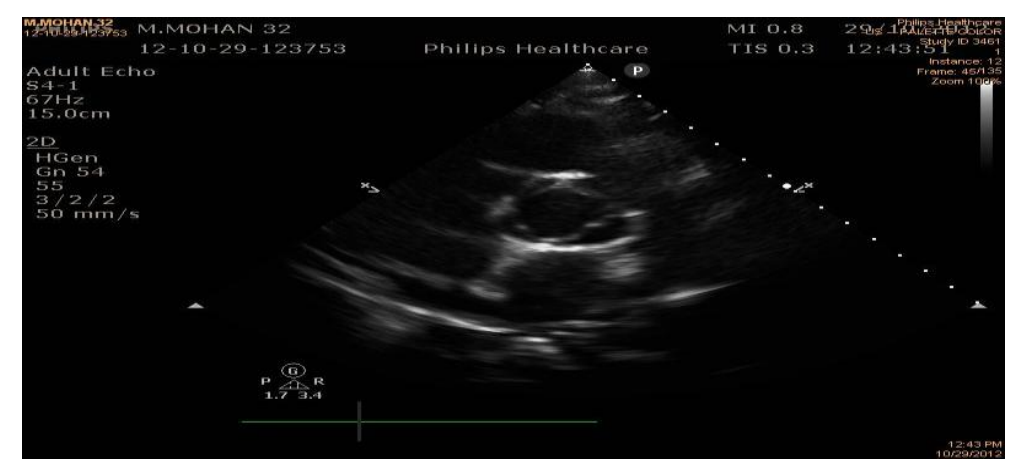

Figure 2: Transthoracic 2 dimensional echocardiogram image in PSAX view at aortic valve in systole showing four leaflets of QAV.

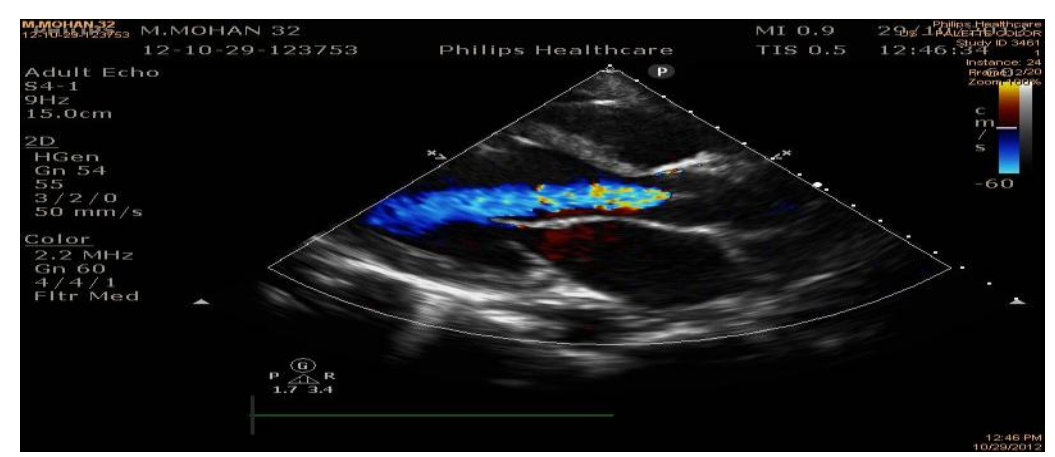

Figure 3: Transthoracic Colour- Doppler echocardiogram image of moderate aortic valve regurgitation associated with the QAV in this case.



Figure 4: Normal surface 12 lead Electrocardiogram in our case. 